\section{SOI: $1.1 /$ TAS $\quad$ DOI: $10.15863 /$ TAS International Scientific Journal Theoretical \& Applied Science}

\author{
p-ISSN: 2308-4944 (print) e-ISSN: 2409-0085 (online) \\ Year: $2015 \quad$ Issue: 03 Volume: 23 \\ Published: $30.03 .2015 \quad$ http://T-Science.org
}

SECTION 32. Jurisprudence.
Zhanna Amangeldinovna Khamzina doctor of Law, professor of the Kazakh National Pedagogical University named after Abay notarius-almaty@ rambler.ru

Yermek Abiltayevich Buribayev doctor of Law of the Kazakh National Pedagogical University named after Abay

Zhambyl Kyluetovich Oryntayev candidate of juridical sciences head of department (BrE) of the Kazakh National Pedagogical University named after Abay $\underline{\text { kamshat5555@mail.ru }}$

\title{
PROBLEMS OF SOCIAL SUPPORT FOR LARGE FAMILIES
}

\begin{abstract}
The relevance of the research issue is conditioned by state and society' being interested in provision of social support to large families, especially with regard to addressing the problems of poverty. There had been made conclusions that we need a complex state approach, development of a special State Program on supporting large families; the concept of having many children shall be revised. It was proposed to consider as large families only those families, in which there are three or more minor children. There were justified statements on insufficiency of the existing norms and measures of large families' social safety net. It was proposed to increase the level of their social security up to the minimum wage.

Key words: many children, social protection, social security, child, subsistence minimum, food basket.

Language: Russian

Citation: Khamzina ZA, Buribayev YA, Oryntayev ZK (2015) PROBLEMS OF SOCIAL SUPPORT FOR LARGE FAMILIES. ISJ Theoretical \& Applied Science 03 (23): 109-114.

Soi: http://s-o-i.org/1.1/TAS*03(23)20 Doi: crossef http://dx.doi.org/10.15863/TAS.2015.03.23.20
\end{abstract}

\section{ПРОБЛЕМЫ СОЦИАЛЬНОЙ ПОДДЕРЖКИ МНОГОДЕТНОЙ СЕМЬИ}

Аннотация: Актуальность темы исследования обусловлена интересами государства и общества в оказании сочиальной поддержки многодетных семей, в особенности в отношении решения проблем бедности. Сделаны выводы о том, что требуется комплексный государственный подход, разработка специальной Государственной программы по поддержке многодетных семей, нуждается в пересмотре понятие многодетность, предложено считать многодетной семью, воспитывающую трех и более несовериеннолетних детей. Обоснованы тезисы о недостаточности существующих форм и мер социальной защчиты многодетных семей. Предложено поднять уровень их социального обеспечения до прожиточного минимума.

Ключевые слова: многодетность, сочииальная защита, сочиальное обеспечение, ребенок, прожиточный минимум, продовольственная корзина.

В современных условиях появление уже первого ребенка в семье повышает риск бедности, а многодетность делает ее бедной в подавляющем числе случаев. И это несмотря на то, что в Республике Казахстан ежегодно увеличивается объем финансирования социальных расходов, принимаются новые меры социальной поддержки семей с детьми. В соответствии с Законом РК «О государственных пособиях семьям, имеющим детей» предусмотрено несколько видов выплат: пособие в связи с рождением ребенка, по уходу за ребенком до достижения им возраста одного года, пособие воспитывающему ребенкаинвалида. Попробуем доказать наш первый тезис-вывод официальными цифрами.

С 2010 года были увеличены размеры пособий, направленных на поддержку семей. Пособие на рождение четвертого и более ребенка увеличилось с 30 до 50 месячных расчетных 
показателей (далее - МРП), пособия по уходу за ребенком до 1 года были увеличены с 5 до 5,5 МРП на первого ребенка, с 5,5 до 6,5 МРП - на второго, с 6 до 7,5 МРП - на третьего и с 6,5 до 8,5 МРП - на четвертого и более ребенка.

С 1 апреля 2014 года размеры пособий по уходу за ребенком и на рождение были дополнительно увеличены и составляют на рождение: первого, второго, третьего ребенка 31,41 месячного расчетного показателя или 62255 тенге в 2015 году; четвертого и более ребенка 52,35 месячного расчетного показателя или 103758 тенге в 2015 году;

пособие по уходу:

на первого ребенка - 5,76 месячного расчетного показателя или 11416 тенге в 2015 году;

на второго ребенка 6,81 месячного расчетного показателя или 13497 тенге;

на третьего ребенка - 7,85 месячного расчетного показателя или 15559 тенге;

на четвертого и более ребенка - 8,90 месячного расчетного показателя или 17640 тенге. Указанные пособия выплачиваются с учетом изменения размера месячного расчетного показателя, устанавливаемого на соответствующий финансовый год законом о республиканском бюджете. При этом прожиточный минимум в 2015 году составляет 21364 тенге.

Пособие по уходу за ребенком назначается на период до достижения ребенком 1 года. Женщина получает данный вид пособия при наступлении такого социального факта как рождение и уход за ребенком, предполагается, что в этот период своей жизни женщина исключается из общественной трудовой деятельности: она занята уходом за ребенком. Соответственно сумма пособия является для матери основным источником средств к существованию, причем не только для нее, но и для ее ребенка. Возникает закономерный вопрос: как можно прожить женщине с ребенком, получая в виде источника средств к существованию сумму в два раза меньшую, чем прожиточный минимум, если это первый ребенок, и сумму значительно меньшую, чем прожиточный минимум, если это пособие на последующих детей? На эти деньги должна существовать не только женщина, но и ее новорожденный ребенок, соответственно размер пособия должен составлять сумму в минимальном исчислении - два прожиточных минимума, чтобы удовлетворить минимальные запросы двух человек: матери и ребенка. Если женщину с ребенком поддерживает материально отец ребенка, семья, тогда создаются более или менее соответствующие условия для полноценного ухода и воспитания новорожденного. Но что делать женщинам, которые лишены данной поддержки? В этом случае рождение ребенка и бедность являются синонимами для женщины, считаем, что в социальном государстве каждый новорожденный имеет право на прожиточный минимум, независимо от уровня доходов родителей. Все сказанное относится к женщинам, не работавшим, не имевшим дохода за два года до оформления пособия.

Для женщин, занятых в трудовых отношениях, индивидуальных предпринимателей, с января 2008 года в рамках системы обязательного социального страхования предусмотрен дополнительный уровень социальной защиты. Работающие женщины, участники системы, имеют право на получение социальной выплаты на случай потери дохода в связи с беременностью и родами в размере среднемесячной заработной платы за все дни отпуска по беременности и родам, а также ежемесячной социальной выплаты по уходу за ребенком до достижения им возраста одного года в размере $40 \%$ от среднемесячного дохода за счет средств Государственного фонда социального страхования.

Указанные выплаты могут быть назначены только работающим женщинам, тем, которым за два года до декрета имели какой-либо заработок, c которого делались отчисления в Фонд социального страхования. При этом размер дохода, из которого исчисляются выплаты, ограничен 10-кратной минимальной заработной платой. Допустим, за женщину делались максимально возможные ежемесячные отчисления в Фонд в 2013 и 2014 годах, то есть с суммы 186600 тенге в 2013 году и с 199660 тенге - в 2014 году. В январе 2015 года женщина оформляет социальную выплату по уходу за ребенком. При этом за основу будет браться средний доход за два года - 193130 тенге, 40 \% от указанной суммы составит 77252 тенге, 10\% от нее будет удержано в качестве обязательных пенсионных взносов, итого женщина будет получать на руки 69527 тенге - это максимально возможная сумма социальных выплат из Фонда в 2015 году, что составляет 3,25 прожиточного минимума. Следует подчеркнуть, что указанный доход рассчитан на содержание двоих: женщины и ребенка, то есть примерно по 1,63 прожиточного минимума на каждого члена семьи. Гипотетически прожить можно, но что это будет за жизнь для матери и ребенка? Тем более с учетом ранее получаемого, до рождения ребенка доходов. Итог жизни на таком уровне - резкое 
падение доходов, бедность ассоциируется с рождением ребенка, необходимостью заботиться о нем, этот вывод реален для всех женщин, как с относительно высокими доходами или вообще не имеющих доход до рождения ребенка.

В целях социальной поддержки малообеспеченных семей с детьми действующим законодательством предусматривается оказание следующих видов социального обеспечения:

1) адресной социальной помощи (далее АСП) - семьям, со среднедушевыми доходами ниже черты бедности (40 \% от прожиточного минимума) в виде разницы между среднедушевым доходом и чертой бедности. То есть АСП будет назначаться, например женщине, воспитывающей ребенка в возрасте до одного года, с единственным источником средств к существованию в размере 11416 тенге - пособием по уходу, в размере 5675 тенге.

2) пособия на детей до 18 лет - семьям, со среднедушевыми доходами ниже стоимости продовольственной корзины $(60 \%$ от прожиточного минимума), в размере 1,05 МРП на каждого ребенка. При этом в выше описанной ситуации размер АСП уменьшится на 2081 тенге, несмотря на применение нового вида социального обеспечения.

3) жилищной помощи - семьям, расходы которых на оплату коммунальных услуг, содержание жилища превышают предельно допустимую долю расходов (на эти цели). Размер и порядок оказания жилищной помощи определяются местными представительными органами.

Таким образом, максимальный ежемесячный доход женщины с одним ребенком составит 17091 тенге плюс жилищная помощь для оплаты коммунальных услуг по установленным социальным нормативам. На этом все возможности материального обеспечения, гарантируемые государством, исчерпаны. Если женщина получает максимально возможные выплаты из Фонда, то ее доход на содержание ребенка не дает право претендовать на АСП, пособие на детей и жилищную помощь.

В соответствии с казахстанским законодательством признается многодетной семья, воспитывающая одновременно 4-х и более несовершеннолетних детей. По уходу за четвертым ребенком до возраста 1 года социальное пособие составляет в 2015 году 17640 тенге, разница между размерами пособия, выплачиваемого на содержание первого и четвертого ребенка, составляет 3,14 МРП или 6224 тенге в 2015 году. Однако социальные выплаты из Фонда не дифференцируется в зависимости от очередности рождения ребенка, формула расчета не изменяется. Приведенная ситуация полагаем, нарушает принцип запрета дискриминации при назначении социальных выплат, поскольку один и тот же социальный факт - рождение ребенка в одном случае увеличивает, а в другом - не изменяет размер социальной помощи.

Помимо вышеперечисленных пособий многодетным семьям, имеющим четырех и более несовершеннолетних детей, выплачивается ежемесячное специальное государственное пособие, составляющее 4,16 МРП или 8245 тенге. В целом доходы женщины, родившей 4-го ребенка, составят в 2015 году в сумме: пособие по уходу 17640 тенге, спецгоспособие 8245 тенге, пособие на детей 8324 тенге, АСП 8519 тенге. Всего в сумме - 42728 тенге, то есть всего лишь величина черты бедности на пятерых (мать и четверо несовершеннолетних детей), даже не прожиточный минимум! Таким образом, высокий риск бедности для семей с детьми - это реальность современного состояния отечественной системы социальной защиты. При этом риск бедности многократно увеличивается, если это многодетная или неполная семья.

Право определения категорий семей, которые относятся к многодетным и нуждаются в дополнительной социальной поддержке, регулируется централизованно. Следует отметить, что многодетность в большинстве стран Европы, в России, Белоруссии, в Украине это воспитание трех и более несовершеннолетних детей. В Казахстане многодетность - это воспитание в семье 4-х и более несовершеннолетних детей. В настоящее время появление ребенка в семье, как правило, существенно снижает уровень ее жизни, а наличие уже трех и более детей делает семью в подавляющем числе случаев бедной [1].

В соответствии с официальными данными доля населения, имеющего доход ниже прожиточного минимума, в процентном соотношении ежегодно уменьшается с 46,7 процентов в 2000 году до 2,9 процентов в 2013 году. При этом если в 2000 году величина прожиточного минимума составляла 28,19 долларов США, то в 2013 - 116,93 долларов США [2].

По данным региональных органов координации занятости населения и социальных программ на 1 января 2015 года АСП назначена 56,1 тыс. гражданам с доходами ниже черты бедности. Доля детей в числе назначении АСП составляет более 64,7 процента, самостоятельно занятых граждан - 7,3 процента, безработных 6,4 и лиц в трудоспособном возрасте $-0,9$. В целом по республике среднемесячный размер 
АСП на одного получателя составляет 1970,7 тенге. Из общего объема средств, направленных для оказания названной государственной помощи 58,1 процента выплачены жителям из сельской местности.

По данным региональных органов координации занятости населения и социальных программ на 1 января 2015 года государственное пособие детям до 18 лет (ГДП) назначено 562,6 тыс. детям, из них доля жителей из сельской местности составляет 72,2 процента. В общем числе назначений четырех видов социальной помощи населению (АСП, ГДП, жилищной помощи, материальное обеспечение детей-инвалидов, воспитывающихся и обучающихся на дому), доля ГДП составляет 75,6 процента. В целом по республике среднемесячный размер ГДП на одного получателя составляет 1402,3 тенге. Из общего объема выплаченных средств около 73,7 процента направлены для получателей из сельской местности. [3].

В сравнении с предыдущим периодом: по итогам 9 месяцев 2014 г. пособием на детей до 18 лет из малообеспеченных семей (ГДП) было охвачено 534,3 тыс. детей, что меньше на $0,9 \%$ по сравнению с аналогичным периодом 2013 года, при этом сумма назначенной ГПД составила 7,1 млрд. тенге. Следует отметить, что из общей суммы выплаченных ГДП направлено детям, проживающим в сельской местности, 72,9 \% [4]. Таким образом, охват детей ГПД вырос на начало 2015 года, пособие стало получать на 28,3 тыс. детей больше в сравнении с 2014 годом.

В соответствии с выше приведенными статистическими данными на 2015 год доля детей в числе лиц, которым назначается АСП, составляет более 64,7 процентов, то есть подавляющее большинство получателей АСП дети, проживающие за чертой бедности. На 1 января 2015 года 562,6 тыс. детям назначено ГДП, а значит 562,6 тыс. детей в Республике имеют доход ниже продовольственной корзины. Общая численность населения Казахстана по данным на 1 февраля 2015 года составляет 17439 271 человек [5], из них несовершеннолетние [6] составляют - 5634503 человека, то есть каждый 10 ребенок в Казахстане не обеспечен доходом, позволяющим приобрести даже месячную продовольственную корзину. Считаем, что эти приведенные данные красноречиво свидетельствуют о необходимости дальнейшего совершенствования мер по социальной защиты многодетных семей.

Доля семей с 3-мя и более детьми с уровнем ежемесячного среднедушевого дохода ниже величины прожиточного минимума является значительной. При этом многодетные семьи, особенно неполные семьи уже с тремя и более детьми, отличаются максимальными риском бедности. Основными причинами бедности многодетных семей являются относительно низкая конкурентоспособность трудоспособных членов таких семей на рынке труда, отчасти обусловленная занятостью в воспитании детей, низкая привлекательность для работодателей принятия на работу граждан с высокой иждивенческой нагрузкой и существенными семейными обязанностями, а также неадекватно низкий уровень социальной помощи, оказываемой органами социальной защиты [7].

Несмотря на стабильный демографический рост, Казахстан занимает 63-е место в списке стран по численности населения. Средняя плотность чуть более 6,39 человек на км², то есть Республика занимает 184-е из 195 мест в списке стран по плотности населения), что обуславливает необходимость особого со стороны общества и государства к положению семей с детьми, обеспечивает государственную заинтересованность в формировании многодетности, как стандарта казахстанской семьи. Изложенное позволяет сформулировать вывод о востребованности снижения планки уровня многодетности: признания многодетными семьи, воспитывающие трех и более несовершеннолетних детей.

Особо отметим, что с 1992 года по 2001 год действовал Указ Президента Республики Казахстан от 4 декабря 1992 года № 1002 (Утратил силу - Указом Президента РК от 4 сентября 2001 г. № 677) «О мерах по социальной поддержке многодетных семей». Данным нормативным правовым актом, в частности, предусматривались такие меры, как: выплата неработающим матерям, имеющим четырех и более детей в возрасте до 7 лет, пособие в размере минимальной заработной платы; бесплатная выдача лекарств, приобретаемых по рецептам врачей, для детей в возрасте до 14 лет; бесплатный проезд на внутригородском транспорте (кроме такси), а также в автобусах пригородных и внутрирайонных линий для матерей и учащихся общеобразовательных школ; преимущественное право на обеспечение по месту работы путевками в санатории, профилактории, дома отдыха; внеочередное обеспечение детей местами в детских дошкольных учреждениях лечебного и санаторного типа и других оздоровительных учреждениях, независимо от ведомственной принадлежности. Главам областных, АлмаАтинской и Ленинской городских администраций поручалось: обеспечить первоочередное 
выделение для многодетных семей приусадебных и садово-огородных участков в размере не менее 0,15 гектара на семью; обеспечить выделение пастбищ, сенокосных угодий и продажу кормов и зерноотходов для скота и птиц, находящихся в личной собственности многодетной семьи, на льготных условиях; оказывать содействие многодетным семьям в случае организации по их желанию крестьянских (фермерских) хозяйств, малых предприятий и других коммерческих структур, обеспечить выделение для этих целей земельных участков; организовать натуральные виды помощи, благотворительные столовые для многодетных семей. Кабинету Министров Республики Казахстан было поручено внести в Верховный Совет Республики Казахстан предложение о внесении изменения в Закон "О занятости населения" в целях продления срока выплаты заработной платы до 6 месяцев после высвобождения с рабочих мест женщинам, имеющим четырех и более детей в возрасте до 18 лет.

Взамен данного нормативного правового акта ничего принято не было. Приведенный Указ действовал в самые тяжелые, 90-е годы прошлого столетия, во времена острейшего экономического, социального кризиса и становления нашей государственности, однако государство брало на себя и выполняло социальные обязательства в отношении многодетных. Почему же сегодня, в периоды стабильного экономического роста, и роста экономики Казахстан даже в условиях мирового финансового кризиса, мы не можем пересмотреть социальные гарантии для многодетных семей? Считаем, что государство должно и может взять на себя ранее выполнявшиеся социальные обязательства с учетом современных достижений развития социальных и экономических отношений.

Анализ нормативной правовой базы в части поддержки многодетных семей на региональном уровне показывает, что эти нормы поддержки многодетных семей в большей своей части устанавливают дополнительные, как правило, разовые выплаты многодетным семьям, при этом определяя различные основания предоставления помощи. Так, Решение маслихата города Павлодара Павлодарской области от 30 апреля 2014 года № 259/35 «Об установлении размеров социальной помощи для отдельно взятой категории получателей к памятным датам и праздничным дням», Решение маслихата города Аксу Павлодарской области от 30 апреля 2014 года № 229/31 «Об установлении размеров социальной помощи для отдельно взятых категорий получателей к памятным датам и праздничным дням» устанавливают выплату единовременной социальной помощи к 8 Марта Международному женскому дню многодетным матерям из числа получателей государственной адресной социальной помощи и государственных пособий семьям, имеющим детей, в размере 2,4 МРП. В соответствии с Решением внеочередной XXI сессии маслихата города Алматы V созыва от 28 ноября 2013 года N 183 «Об установлении размеров социальной помощи и определении перечня отдельных категорий нуждающихся граждан» многодетные семьи имеют право на социальную помощь на возмещение затрат за приобретение, установку или поверку индивидуальных приборов учета горячего и (или) холодного водоснабжения предоставляется нижеследующим гражданам, имеющим среднедушевой доход, не превышающий величину трехкратного прожиточного минимума в размере, не превышающем 2 МРП за один прибор; согласно Постановлению акимата Мангистауской области от 04 ноября 2010 года № 384 «О назначении социальной помощи студентам, обучающимся по востребованным в регионе специальностям» студенты из многодетных семей имеют право на получение социальной помощи. Решение маслихата города Астана от 27 июня 2014 года № 251/36-V «O Порядке оказания социальной помощи отдельным категориям граждан города Астана в виде освобождения от оплаты проезда на маршрутах городского пассажирского транспорта» закрепляет, что социальная помощь отдельным категориям граждан города Астана в виде освобождения от оплаты проезда на маршрутах городского пассажирского транспорта оказывается гражданам, зарегистрированным и постоянно проживающим в городе Астана, оказывается многодетным матерям и многодетным семьям.

Завершая обзор региональных форм поддержки многодетных семей, следует отметить региональное неравенство в доступе к ним, в целом, можно констатировать, что отсутствует единое социальное пространство в части государственной поддержки многодетных семей, a ее содержание и уровень зависят от места проживания многодетной семьи.

Провозгласив Казахстан социальным государством, Конституция прямо указывает, что в нашей стране охраняются труд и здоровье людей, обеспечивается государственная поддержка семьи, материнства, отцовства и детства, гарантируются социальные права инвалидов, лиц, потерявших кормильца, пожилых людей. Несмотря на то, что все эти положения нашли свое отражение в 
действующем законодательстве, конечно, огромное количество проблем еще не решено, государство пытается их реализовывать поэтапно, исходя из возможностей бюджета, текущей экономической ситуации. При этом развитие в Казахстане социального государства предполагает приобретение первостепенного значения исполнения государством его социальных обязательств, проведения эффективной социальной политики [8]. Все эти задачи требуют взвешенного подхода и полноценного развития законодательства в области совершенствования правового регулирования социальной поддержки многодетных семей.

Необходимо создавать условия для жизни многодетных семей. Требуется комплексный государственный подход, разработка специальной Государственной программы, которая включала бы в себя такие направления, как внедрение дополнительных налоговых льгот для многодетных, пособий для оплаты детских дошкольных учреждений, перспективным направлением является рассмотрение вопроса о снижении пенсионного возраста для матерей, за каждого ребенка, что особо актуально в преддверии повышения пенсионного возраста женщин. Считаем, что государственная политика в данном направлении должна быть направлена на формирование и реализацию стремления женщины облегчить сочетание работы и семейной жизни, с тем, чтобы, в первую очередь, государственный подход был направлен, в конечном счете, на противостояние бедности; на повышение уровня занятости женщин, ставя под сомнение меры, побуждающие женщин уходить с рынка труда.

\section{References:}

1. Khamzina ZA, Khamzin AS (2010) Problemy deyatelnosty gosudarstva po obespecheniyu socialnyh prav cheloveka v Kazakhstane: Monographya. Astana, 2010. - 386 p.

2. (2015) Ministry of National Economy of the Republic of Kazakhstan Committee on Statistics. Available: http://stat.gov.kz (Accessed: 20.03.15).

3. (2015) O gosudarstvennoy sotsial'noy pomoshchi na 1 jan 2015. Available: http://www.mzsr.gov.kz/node/321264

(Accessed: 20.03.15).

4. (2015) Doclad o pologeniy detey v Respublice Kazakhstan (2014). Available: http://www.balakkk.kz/ru/node/351 (Accessed: 20.03.15).

5. (2015) The ministry of healthcare and social development of the republic of kazakhstan:
Available: $\quad$ http://www.mzsr.gov.kz/ (Accessed: 20.03.15).

6. (2015) Committee on Child Protection. Ministry of Education and Science of the Republic of Kazakhstan. Available: http://www.bala-kkk.kz/ru/ (Accessed: 20.03.15).

7. Khamzina ZA (2015) Actualnye napravlenya sovershenstvovanya socialnogo zakonodatelstva. Available: http://online.zakon.kz/Document/?doc_id=3150 1578 (Accessed: 20.03.15).

8. Khamzina ZA, Khamzin AS (2015) Socialnye prava - osnovnye prava. Available: http://online.zakon.kz/Document/?doc_id=3079 7833 (Accessed: 20.03.15). 